BANGLADESH J CHILD HEALTH 2011; VOL 35 (2): 59-61

\title{
Anderson-Hynes Pyeloplasty in Children: Nonintubated Versus Intubated
}

\author{
GAZI ZAHIRUL HASAN ${ }^{1}$, AKM ZAHID HOSSAIN ${ }^{1}$, MD. RUHUL AMIN², \\ SHAFIQUL HOQUE ${ }^{3}$, MTH SIDDIQUI ${ }^{2}$
}

\begin{abstract}
Objective: To compare between nonintubated versus intubated Anderson-Hynes (AH) pyeloplasty in children.
\end{abstract}

Study Design: Prospective study

Study place: Department of Paediatric Surgery, Bangabandhu Sheikh Mujib Medical University (BSMMU), Dhaka, Bangladesh and some private clinics of Dhaka city.

Study period: March 2001 to December 2008.

Subjects: A total of 75 patients were included in this study. They were divided in two groups. Nonintubated Anderson-Hynes pyeloplasty was done in 45 patients and intubated Anderson-Hynes pyeloplasty was done in 30 patients.

Results: The anastomotic leakage of urine, urinary tract infection, hospital stay and improvement of differential renal function were assessed post operatively in both nonintubated and intubated groups. This study showed that there was no anastomotic failure and no post operative urinary tract infection in either group. The percentage of improvement of differential renal function is almost same in both the groups. The post operative hospital stay was markedly reduced in nonintubated Anderson-Hynes pyeloplasty. In this study the post operative hospital stay in nonintubated group was average 6 days and it was average 16.5 days in intubated group.

Conclusion: From this study it may be concluded that the effects of nonintubated A$H$ pyeloplasty is as good as intubated one but an additional advantage of significantly less post operative hospital stay was observed in nonintubated group.

Key words: Intubated, Nonintubated, pyeloplasty, children

\section{Introduction}

Intrinsic pelviureteric junction obstruction is the commonest cause of hydronephrosis in children ${ }^{1}$. Although there are many types of surgical procedures done for the correction of this anomaly, the AndersonHynes pyeloplasty is the most common ${ }^{2}$ but controversy remains regarding the diversion of urine after $\mathrm{A}-\mathrm{H}$ pyeloplasty ${ }^{3}$. Now a days, there is an increasing trend to do the $\mathrm{A}-\mathrm{H}$ pyeloplasty nonintubatedly in children $2,4,5$. Because most of the surgeons believe that nephrostomy/ pyelostomy tube

1. Assistant Professor, Department of Paediatric Surgery, Bangabandhu Sheikh Mujib Medical University

2. Associate Professor, Department of Paediatric Surgery, Bangabandhu Sheikh Mujib Medical University

3. Professor and Chairman, Department of Paediatric Surgery, Bangabandhu Sheikh Mujib Medical University

Correspondence: Gazi Zahirul Hasan or stent are found to be unnecessary if watertight closure of the anastomosis is achieved ${ }^{3}$. Moreover intubated $\mathrm{A}-\mathrm{H}$ pyeloplasty has been alleged to have more disadvantages, e.g, more postoperative hospital stay, increased incidence of postoperative urinary tract infection, difficulties in patient mobilization ${ }^{2,4,5,6}$. They also assumed that the patency of the pelviureteric anastomosis is best ensured by encouraging the urine to pass through the anastomosis as early as possible ${ }^{4}$.

\section{Materials and Methods}

This prospective study was carried out in the Department of Paediatric Surgery, Bangabandhu Sheikh Mujib Medical University and in some private clinics of Dhaka city during the period of March 2001 to December 2008. Seventy five (75) patients were 
included in this study, Forty five (45) patients have undergone nonintubated A-H pyeloplasty and (30) patients undergone intubated $\mathrm{A}-\mathrm{H}$ pyeloplasty. The age range in nonintubated group was 2 months to 12 years with a mean of 4.3 years and in intubated group it was between 3 months to 11 years with a mean of 4.39 years. Left kidney involvement was more in both the groups. A-H pyeloplasty was advised in all symptomatic patients of unilateral hydronephrosis having split renal function between $10-40 \%$. After A-H pyeloplasty, the anastomotic leakage of urine which comes out through the paraanastomotic drain tube was measured daily and total days of leakage were noted. Urine for $R / M / E$ and $C / S$ were done on $3^{\text {rd }}$ postoperative day.

Total days of postoperative hospital stay was recorded in both groups. After 3 months of operation, urine for $\mathrm{R} / \mathrm{M} / \mathrm{E} \& \mathrm{C} / \mathrm{S}$, USG of the kidney and DTPA renogram study with split renal function was done.

\section{Observation and Results}

The postoperative anastomotic leakage of urine was measured daily and the total days of leakage was noted. In the nonintubated group, 5 (11.1\%) patients had no paraanastomotic drainage of urine, $17(37.7 \%)$ patients had paraanastomotic drainage of urine for 1 day and 22 (48.9\%) patients had 2 days and in another $1(2.2 \%)$ patient, drainage continued for 8 days which then stopped spontaneously. The average days of paraanastomotic urinary leakage in nonintubated group was 1.53 days.

In intubated group, $9(30 \%)$ patients had no paraanastomotic drainage of urine, $6(20 \%)$ patients had 1 day, $9(30 \%)$ patients had 2 days and $6(20 \%)$ patients had 3 days. The average days of paraanastomotic urinary leakage in this group was 1.4 days. Thus the difference of paraanastomotic leakage between the two groups were not significant. The duration of post operative paraanastomotic drainage of urine between nonintubated and intubated pyeloplasty is shown in table $\mathrm{I}$.

In both nonintubated and intubated group, the urine for $\mathrm{R} / \mathrm{M} / \mathrm{E}$ and $\mathrm{C} / \mathrm{S}$ was done on $3^{\text {rd }}$ post operative day. Urine for R/M/E of both groups were normal and their urine culture were also negative for bacterial growth.

\section{Table-I}

Relationship of post operative paraanastomotic drainage of urine between nonintubated and intubated pyeloplasty

\begin{tabular}{llccc}
\hline $\begin{array}{l}\text { Type of } \\
\text { pyeloplasty }\end{array}$ & $\begin{array}{l}\text { Mean days of } \\
\text { paraanastomotice } \\
\text { urinary drainage }\end{array}$ & DF & $\begin{array}{c}\text { ' } \mathrm{y} \text { ' } \\
\text { value }\end{array}$ & $\begin{array}{c}\mathrm{P} \\
\text { value }\end{array}$ \\
\hline $\begin{array}{l}\text { Nonintubated } \\
(\mathrm{n}=45)\end{array}$ & 1.53 days & 13 & 0.04 & $>0.1$ \\
Intubated & & & & \\
& & 1.4 days & &
\end{tabular}

$(\mathrm{n}=30)$

$P$ value is reached by unpaired students ' $\mathrm{t}$ ' test

( $P$ value is not significant)

In the non intubated group, the patients were discharged 2 days after removal of the paraanastomotic drain tube. In this group, minimum postoperative hospital stay was 5 days and the maximum was 12 days. The average post operative hospital stay was 6 days.

In the intubated group, the patients were discharged 2 days after removal of nephrostomy tube. In this group, the minimum postoperative hospital stay was 12 days and the maximum postoperative hospital stay was 32 days. The average postoperative hospital stay was 16.5 days. The difference of postoperative hospital stay between the two groups were very significant. The duration of post operative hospital stay between nonintubated and intubated pyeloplasty is shown in Table II.

Table-II

Relationship of post operative hospital stay between nonintubated and intubated pyeloplasty.

\begin{tabular}{lllcc}
\hline $\begin{array}{l}\text { Type of } \\
\text { pyeloplasty }\end{array}$ & $\begin{array}{l}\text { Mean Hospital } \\
\text { stay (days) }\end{array}$ & DF & $\begin{array}{c}\text { 't' } \\
\text { value }\end{array}$ & $\begin{array}{c}P \\
\text { value }\end{array}$ \\
\hline Nonintubated & 6 & 23 & 3.04 & $<0.01$ \\
$(n=45)$ & & & & \\
Intubated & 16.5 & & & \\
$(n=30)$ & & & & \\
\hline
\end{tabular}

$P$ value is reached by unpaired students ' $t$ ' test ( $P$ value is very significant

DTPA renogram study with split function was done to evaluate the differential renal function after 3 months 
of operation and it is compared with the preoperative DTPA results. In the nonintubated group, the largest percentage of improvement of renal function was $14 \%$ and the lowest was $3 \%$. The mean percentage of improvement of renal function was $8.93 \%$. In the intubated group, the largest percentage of improvement was $15 \%$ and the lowest was $6 \%$ with a mean of $8 \%$ improvement.

\section{Discussion}

In this study, 75 patients were taken as sample volume. Forty five (45) patients were undergone nontubated Anderson-Hynes pyeloplasty and 30 patients were undergone intubated Anderson-Hynes pyeloplasty. In both the groups, left kidney involvement were more. This study correlated with the study conducted by Bejjani et $\mathrm{al}^{7}$. The average days of postoperative paraanastomotic urinary leakage was 1.53 days in nonintubated group and it was 1.4 days in the intubated group. This indicates that the difference of paraanastomotic urinary leakage in both the nonintubated and intubated group is not significant. $P$ value is more than 0.1 . This study correlates with other studies $^{3}$. These observation also showed that there was no anastomotic failure in both nonintubated and intubated A-H pyeloplasty. Postoperative urinary tract infection was not developed in any group. Postoperative urinary tract infection is defined as greater than $10^{5}$ bacteria per $\mathrm{ml}$ of urine. Although Rickwood ${ }^{3}$ and Wollin ${ }^{4}$ showed more incidence of UTI in presence of foreign body like nephrostomy tubes or stents but Nguymen ${ }^{2}$ reported that with the use of antibiotic, the incidence of postoperative urinary tract infection is not affected by intubated and nonintubated repair.

In this study, the average postoperative hospital stay in nonintubated group was 6 days and it was 16.5 days in intubated one. The difference of hospital stay between the nonintubated and intubated pyeloplasty was highly significant $(P<0.01)$. This study correlated with the other studies ${ }^{2,5,7}$. The study conducted by Nguyen $^{2}$ proved that postoperative hospital stay after nonintubated and intubated A-H pyeloplasty was 4.3 days and 12 days respectively. The study reports of Hossain ${ }^{5}$ was 5.4 days in nonintubated cases and 12.1 days in intubated cases. The study reports of Bejjani $^{7}$ was 4.8 days and 15 days in nonintubated and intubated cases respectively.

The child with the stents or nephrostomy tubes can also be discharged after 3-4 days of operation and the tubes can be managed at home on out patient basis. But we are mostly dealing with the illiterate section of the society. So out patient management of drain is virtually impossible in our country.

The mean percentage of improvement of renal function was 8.93 days in nonintubated group and it was $8 \%$ in intubated group. The difference of percentage of improvement of differential renal function is not significant in both the group. The study correlated with the other studies ${ }^{3,4}$.

\section{Conclusion}

This study showed that both nonintubated and intubated $\mathrm{A}-\mathrm{H}$ pyeloplasty are safe and effective procedure. A nonintubated A-H pyeloplasty also gives an additional advantage of less hospital stay. The duration of hospital stay is an important issue in our country, because we have limited hospital bed and lot of patient load. Moreover, as the tube is a foreign body and there is no additional advantages of intubated A$\mathrm{H}$ pyeloplasty, such drainage may be avoided.

\section{References}

1. Hanna MK, Jeffs RD, Sturgess JM, Barkin M. Jennifer M. Ureteral structure and ultrastructure, congenital ureteropelvic junction obstruction and primary obstructive megaureter. J Urol 1976; 116(6): 725-730

2. Nguyen $\mathrm{DH}$, Aliabadi H, Ercole CJ, Gonzalez R. Nonintubated Anderson-Hynes pyeloplasty of ureteropelvic junction obstruction in 60 patients J Urol 1989; 142(3): 704-06.

3. Rickwood AMK, Phadke D. Pyeloplasty in infants and children with particular reference to the method of drainage post operatively. $\mathrm{Br} \mathrm{J}$ Urol 1978; 50(4): 217-21.

4. Wollin M, Duffy P, Diamond DA: Priorities in urinary diversion following pyeloplasty. $J$ Urol 1989; 142: 576-8.

5. Hussain S, Frank Jed. Complication and length of hospital stay following stented and unstented paediatric pyeloplasty. Brj Urol 1994; 73(1): 87-9.

6. Sheldon, Ducket JW, Snyder HM. 'Evolution in the management of infant pyeloplasty'. J Paediatr Surg int 1992; 27(4): 501-505.

7. Bejjani B, Belman. Uretero-pelvic junction obstruction in newborn and infants $J$ Urol 1982; 128(4): 770-2.

8. Sarin YK, Gupta R, Nagdeve N. Pediatric pyeloplasty: Intubated vs nonintubated Indian J of Urol 2006; 22(1): 35-8. 